\title{
A Method for the Quantification of Intracellular Zidovudine Nucleotides
}

\author{
Herbert Kuster, Markus Vogt, Beda Joos, Vera Nadai, \\ and Ruedi Luithy
}

Division of Infectious Diseases, Department of Medicine, University Hospital. Zurich, Switzerland

\begin{abstract}
An assay to quantify the phosphorylation products of zidovudine (AZT) in peripheral blood mononuclear cells (PBMC) was developed. Extracts of PBMC were separated by high-performance liquid chromatography. Eluted AZT mono- (MP), di- (DP), and triphosphate (TP) were collected in separate portions. Treatment with alkaline phosphatase yielded equimolar amounts of AZT, which after solid-phase enrichment were assayed by radioimmunoassay. Detection limit was $0.1 \mathrm{pmol} / 10^{6}$ PBMC for each nucleotide. Recoveries of $102 \%-118 \%$ were observed. AZT nucleotides were measured in samples from three patients receiving $250 \mathrm{mg}$ of AZT every $12 \mathrm{~h}$. Intracellular concentrations of AZT-MP after $1-2 \mathrm{~h}$ ranged from 0.9 to $1.4 \mathrm{pmol} / 10^{6} \mathrm{PBMC}$ and then declined to 0.3-1.1 pmol/10 ${ }^{6}$ PBMC after $4 \mathrm{~h}$. AZT-DP and AZT-TP reached concentrations of 0.3-0.5 pmol/10 $10^{6}$ PBMC after 1-2 $\mathrm{h}$ and could not be detected after $4 \mathrm{~h}$ in any of the three patients. Duplicate determinations deviated by $<20 \%$.
\end{abstract}

Zidovudine (3'-azido-3'-deoxythymidine; AZT) has been shown to improve survival in patients with AIDS and advanced AIDS-related complex [1]. The compound is a thymidine analog that is efficiently converted intracellularly to AZT-5'-monophosphate (AZT-MP) by thymidine kinase. AZT-MP is then further phosphorylated by thymidylate kinase to the 5'-diphosphate (DP) form and finally to AZT-5'triphosphate (AZT-TP) [2]. AZT-TP is assumed to be the active form of the drug as it competitively inhibits viral reverse transcriptase [2-4] and further causes proviral DNA chain termination [5].

Serum pharmacokinetics of AZT have been studied extensively [6]; however, no data about the extent and kinetics of in vivo phosphorylation are available. To date the intracellular anabolism of AZT and of other dideoxynucleosides has been examined only in vitro using radiolabeled compounds $[2,7-9]$. A detailed knowledge about the in vivo phosphorylation is important for several reasons. First, there is a documented variability of AZT phosphorylation in various cell systems [8], and data from in vitro experiments cannot necessarily be extrapolated to the in vivo situation. Second, interindividual differences in drug metabolism are well known in clinical medicine for a variety of compounds, and it is conceivable that differences in phosphorylation may at least

Received 5 February 1991: revised 3 May 1991.

Presented in part: 30th Interscience Conference on Antimicrobial Agents and Chemotherapy. Atlanta. 1990 (abstract 625).

Informed consent was obtained from all study subjects: guidelines of the University Hospital Fthical Committee were followed

Grant support: Swiss National Science Foundation (3.584-0.87. 31 . 9169.87).

Reprints or correspondence: Dr. Ruedi Lüthy. Division of Infectious Diseases, Department of Medicine, University l Iospital, CH-8091 Zürich, Switzerland.

The Journal of Infectious Diseases 1991;164:773-6

(C) 1991 by The University of Chicago. All rights reserved

$0022-1899 / 91 / 6404-0023 \$ 01.00$ partly explain the observed differences in the toxicity profile and the clinical and virologic response. Finally, a better understanding of the in vivo pools and pharmacokinetics of intracellular AZT-TP might lead to improved drug schedules for individual patients. Thus we developed a method to measure the intracellular anabolites of AZT in whole blood from patients treated with this drug.

\section{Materials and Methods}

Preparation of cell extracts. From patients receiving $250 \mathrm{mg}$ of AZT every $12 \mathrm{~h}$ or from healthy human immunodeficiency virus (HIV)-seronegative controls, peripheral blood mononuclear cells (PBMC) from $20 \mathrm{ml}$ of heparinized venous blood were separated by ficoll-hypaque density gradient centrifugation. Aliquots of plasma were stored frozen at $-20^{\circ} \mathrm{C}$ for subsequent determination of AZT concentrations by RIA. Cells were washed twice with cold PBS and counted by trypan blue dye exclusion. Nucleotides were extracted twice with $250 \mu \mathrm{l}$ of 0.33 $\mathrm{mol} / \mathrm{l}$ perchloric acid.

After neutralization of combined extracts with trioctylaminefreon [10], the ribonucleotides were degraded by adding $20 \mu \mathrm{l}$ of $0.2 \mathrm{~mol} / \mathrm{l}$ sodium periodate, followed after $2 \mathrm{~min}$ by $30 \mu \mathrm{l}$ of 3 $\mathrm{mol} / \mathrm{l}$ glycine. After mixing, extracts were incubated at $40^{\circ} \mathrm{C}$ for $\mathrm{l} \mathrm{h} ; 2 \mu \mathrm{l}$ of $\mathrm{l} \mathrm{mol} / \mathrm{l}$ rhamnose was then added, and the samples were put on ice or stored frozen at $-20^{\circ} \mathrm{C}$.

Separation of AZT nucleotides. Aliquots of extracts $(200 \mu \mathrm{l}$, corresponding to $6.8-16.5 \times 10^{6} \mathrm{PBMC}$ ) were separated by ion exchange high-performance liquid chromatography (HPLC) on a $5-\mu \mathrm{m}$ column $(250 \times 4.6 \mathrm{~mm}$; Supclcosil LC-SAX: Supelco, Bellefonte, PA). A linear gradient from 12 to $120 \mathrm{mmol} / \mathrm{l}$ potassium dihydrogen phosphate $\left(\mathrm{KH}_{2} \mathrm{PO}_{4}\right)$ was applied within 10 min at a flow rate of $2 \mathrm{ml} / \mathrm{min}$. Three fractions of the eluate (4 $\mathrm{ml}$ each) containing the AZT-MP, AZT-DP, or AZT-TP. respectively, were collected.

Collection periods were established by chromatographing a mixture of all three AZT nuclcotides using UV detection at 267 $\mathrm{nm}$. Beginning and end times were extended by at least 0.2 and $0.5 \mathrm{~min}$ on the front and back side of the peaks. This standard 
solution was freshly prepared by adding 0.07 units of alkaline phosphatase (bovine type I-S; Sigma, St. I ouis) to $100 \mu$ l of 4.25 $\mu \mathrm{mol} / \mathrm{l}$ AZT-TP (Burroughs Wellcome, Research Triangle Park, NC). After each series of separations the column was flushed with $400 \mathrm{mmol} / \mathrm{l}$ phosphoric acid for $10 \mathrm{~min}$ to avoid peak broadening due to column aging.

Hydrolysis of AZT nucleotides. After addition of $1 \mathrm{ml}$ of 1 $\mathrm{mol} / \mathrm{l}$ TRIS, $\mathrm{pH} 8.8$, and 17.5 units of alkaline phosphatase, fractions were incubated at $37^{\circ} \mathrm{C}$ for $24 \mathrm{~h}$.

Solid-phase extraction of $A Z T$. Hydrolyzed samples were loaded onto a SepPak C1 8 cartridge (Waters, Milford, MA) preconditioned with $5 \mathrm{ml}$ of methanol followed by $10 \mathrm{ml}$ of distilled water. After washing with $10 \mathrm{ml}$ of distilled water, AZT was eluted with $2 \mathrm{ml}$ of methanol.

Quantification of $A Z T$. Methanol was removed by vacuum centrifugation (Speed Vac; Savant, Farmingdale, NY). The residue was reconstituted in $200 \mu$ l of RIA buffer. Amounts of AZT were determined by RIA (ZDV-Trac RIA; Incstar, Stillwater, $\mathrm{MN}$ ) according to the manufacturer's instructions. Standard samples containing $1.1,2.3,4.6,10,20,76$, and $272 \mathrm{pmol}$ of AZT-TP in $200 \mu 1$ of distilled water were assayed in duplicate as described for neutralized extracts. Calibration curves were constructed by plotting RIA counts against logarithms of standard amounts. Results of unknown samples were normalized to $10^{6}$ PBMC based on cell counts and volumes of extracts.

Determination of analytical recovery. Blood samples from an untreated control were processed as described above, except that known amounts of AZT-TP were added to the cell pellet before perchloric acid extraction.

Cell cultures. PBMC $\left(20 \times 10^{6}\right)$ from a healthy HIV-seronegative blood donor were cultured for $24 \mathrm{~h}$ in $20 \mathrm{ml}$ of RPMI 1640 medium (GIBCO BRL, Basel, Switzerland) supplemented with $20 \%$ fetal bovine serum (Inotech, Wohlen, Switzerland) and $10 \%$ interleukin-2 (200 units/ml; Boehringer Mannheim, Mannheim, Germany) in the presence of $2 \mu \mathrm{mol} / 1\left[{ }^{3} \mathrm{H}\right] \mathrm{AZT}$ ( $500 \mathrm{dpm} / \mathrm{pmol}$; cultures I and II) or $2 \mu \mathrm{mol} / 1$ cold AZT (culture III). Antibiotics were omitted. Cells were collected from the same blood donor for all three batches. Thereafter, cells were harvested by centrifugation at $600 \mathrm{~g}$ for $10 \mathrm{~min}$ (cultures I and III) or by ficoll separation (culture II). AZT nucleotides in cell extracts were quantified in duplicate by liquid scintillation counting of HPLC eluates (cultures I and II) [11] or by the method described above (culture IIl).

\section{Results}

Log-logit transformed calibration curves obtained with AZT-TP were linear from 1.1 to 272 pmol $(r<-990)$. Lower amounts were not detectable. Analytical recoveries from blank PBMC spiked with known amounts of AZT-TP are shown in table 1. Duplicate determinations deviated by $<15 \%$.

In PBMC cultured in the presence of $2 \mu \mathrm{mol} / 1\left[{ }^{3} \mathrm{H}\right] \mathrm{AZT}$ for $24 \mathrm{~h}$, concentrations of AZT-MP, AZT-DP, and AZT-TP were $193,1.3$, and $2.0 \mathrm{pmol} / 10^{6} \mathrm{PBMC}$, respectively, after ficoll-hypaque density-gradient centrifugation. If cells were
Table 1. Recovery from cell extracts spiked with zidovudine triphosphate.

\begin{tabular}{lcc}
\hline $\begin{array}{c}\text { Zidovudine (pmol/10 } \\
\text { blood mononuclear cells) }\end{array}$ & \\
\cline { 1 - 2 } Spiked & Found & \% recovery \\
\hline 0.20 & 0.23 & 115 \\
0.50 & 0.54 & 108 \\
1.4 & 1.5 & 107 \\
2.0 & 2.4 & 118 \\
5.0 & 5.1 & 102 \\
\hline
\end{tabular}

NOTE. Data are means of duplicate determinations.

harvested by simple centrifugation, concentrations of 215 , 1.7 , and $1.6 \mathrm{pmol} / 10^{6} \mathrm{PBMC}$ were found. PBMC of the same donor treated under identical conditions but with unlabeled AZT yielded concentrations of $198 \mathrm{pmol} / 10^{6} \mathrm{PBMC}$ for AZT-MP, $1.8 \mathrm{pmol} / 10^{6} \mathrm{PBMC}$ for AZT-DP, and $2.4 \mathrm{pmol} /$ $10^{6} \mathrm{PBMC}$ for AZT-TP by RIA. These results rule out excessive loss of $A Z T$ nucleotides during sample preparation.

AZT-MP, -DP, and -TP were well separated by HPLC. Mean retention times of 5.38, 7.87, and $9.49 \mathrm{~min}$, respectively, were observed, with only minor run-to-run variability within the same day ( $\mathrm{SD}<0.1 \mathrm{~min}$ ).

Blood samples were obtained from three patients on longterm oral therapy with $250 \mathrm{mg}$ of AZT every $12 \mathrm{~h}$. AZT nucleotides were determined before and 1,2 , and $4 \mathrm{~h}$ after administration of the drug. No phosphorylation products were found before administration.

Intracellular concentrations of AZT-MP after $1-2 \mathrm{~h}$ were 0.9-1.4 pmol/10 $0^{6}$ PBMC and then declined to 0.3-1.1 $\mathrm{pmol} / 10^{6}$ PBMC after $4 \mathrm{~h}$. AZT-DP and AZT-TP reached concentrations of $0.3-0.5 \mathrm{pmol} / 10^{6} \mathrm{PBMC}$ after $1-2 \mathrm{~h}$ and could not be detected after $4 \mathrm{~h}$ in any of the three patients (table 2).

\section{Discussion}

Quantification of intracellular AZT nucleotides has so far been done only in cell cultures treated with $\left[{ }^{3} \mathrm{H}\right] \mathrm{AZT}[2$, 7-9]. Since radiolabeling is not feasible in human pharmacokinetic studies, a method was developed that uses the selectivity of HPLC to separate mono-, di-, and triphosphate and the sensitivity of a commercially available RIA to quantify them in PBMC obtained from patients treated with AZT.

Cell extracts contain large amounts of natural ribonucleotides, which in part coelute with AZT nucleotides in HPLC. They were destroyed by periodate oxidation [12] to limit potentially cross-reacting contaminations of RIA samples. Alkaline phosphatase activity is inhibited by inorganic phosphates present in the elution buffer. Large amounts of the 
Table 2. Phosphorylation of zidovudine (AZT) in three patients receiving $250 \mathrm{mg}$ every $12 \mathrm{~h}$.

\begin{tabular}{ccccc}
\hline Patient, h & $\begin{array}{c}\text { Plasma AZT } \\
(\mu \text { mol/1 })\end{array}$ & AZT-MP & AZT-DP & AZT-TP \\
\hline 1,0 & $<0.03$ & $<0.1$ & $<0.1$ & $<0.1$ \\
1 & 2.22 & 1.2 & 0.3 & 0.2 \\
2 & 0.72 & 1.4 & 0.3 & 0.3 \\
4 & 0.25 & 1.1 & $<0.1$ & $<0.1$ \\
2,0 & $<0.03$ & ND & ND & ND \\
1 & 2.98 & 0.9 & 0.3 & 0.3 \\
2 & 0.61 & 0.6 & 0.2 & 0.2 \\
4 & 0.10 & 0.3 & $<0.1$ & $<0.1$ \\
3,0 & $<0.03$ & $<0.1$ & $<0.1$ & $<0.1$ \\
1 & 0.81 & 0.7 & $<0.1$ & 0.2 \\
2 & 2.17 & 1.1 & 0.5 & 0.5 \\
4 & 0.77 & 1.0 & $<0.1$ & $<0.1$ \\
\hline
\end{tabular}

NOTE. Values are means of duplicate determinations that deviated by $<20 \%$. AZT-MP (monophosphate), -DP (diphosphate), and -TP (triphosphate) concentrations are given in pmol $/ 10^{6}$ peripheral blood mononuclear cells. $\mathrm{ND}=$ not done.

enzyme and long incubation times are therefore required to obtain equimolar amounts of AZT from AZT-MP, -DP, and -TP. Recovery experiments showed the feasibility of our approach (table 1). AZT-TP concentrations found were always slightly above the expected value. Considering multiple sample manipulations and the lack of an internal standard, accuracy appears satisfactory.

Since the cell membrane is partly permeable for AZT-MP [13], and isolation of PBMC from whole blood takes $\sim \mathrm{lh}$, we suspected a partial loss of intracellular AZT-MP may occur. However, no change in AZT-MP concentration and no hydrolysis of AZT-TP was observed when $\left[{ }^{3} \mathrm{H}\right] \mathrm{AZT}$-labeled PBMC were harvested from cell cultures by ficoll-hypaque separation. Analyzing AZT nucleotide pools of PBMC grown in the presence of $\left[{ }^{3} \mathrm{H}\right] \mathrm{AZT}$ or AZT by either HPLC and liquid scintillation counting or HPLC-RIA yielded comparable results. AZT-TP concentrations measured in patient cells suggest a rapid decay in vivo (table 2 ). This contrasts with an in vitro study [7] using a leukemic $\mathrm{T}$ cell line in which an intracellular half-life for AZT-TP of 200 min was observed. A possible explanation may be the finding by Balzarini et al. [8] that intracellular metabolism of AZT is highly dependent on the cell species [8].

Stretcher et al. $[14,15]$ measured the concentration of total phosphorylated AZT (i.e., AZT-MP, -DP, and -TP) in PBMC of patients receiving AZT at a dose of $500 \mathrm{mg} / \mathrm{day}$. In 14 samples obtained from 12 patients at various time points, concentrations of $0.3-4 \mathrm{pmol} / 10^{6}$ cells were found. Pooled data from that population showed no decrease in total phosphorylated AZT over $3.5 \mathrm{~h}$ so the authors concluded that the decay of phosphorylated AZT was slow. Nevertheless, since AZT-MP is the most abundant phosphorylation product and the ratio between mono- and triphosphate appears inconstant (table 2), changes in the AZT-TP concentration will not necessarily be detected by that assay.

Assuming a mean cellular volume of $0.25 \mathrm{pl}$, the detection limit of $0.1 \mathrm{pmol} / 10^{6} \mathrm{PBMC}$ corresponds to an intracellular concentration of $0.4 \mu \mathrm{mol} / \mathrm{l}$. Data from various studies indicate that AZT-TP may affect viral transcription at concentrations below the detection limit of our assay. Competitive inhibition of human immunodeficiency virus type 1 reverse transcriptase (HIV-RT) by AZT-TP has been studied by several groups $[2-4]$. Depending on the primer template used, $K_{\mathrm{i}}$ values ranging from $0.01 \mu \mathrm{mol} / 1$ (for HIV RNA) to 0.3 $\mu \mathrm{mol} / \mathrm{l}$ (for activated calf thymus DNA) were reported, which suggests that considerable inhibition of HIV-RT occurs even at concentrations $<0.4 \mu \mathrm{mol} / \mathrm{l}$.

Huang et al. [5] studied the incorporation of AZT-TP into a DNA primer by HIV-RT in vitro. They observed termination of primer elongation even when the AZT-TP concentration was $0.3 \mu \mathrm{mol} / 1,100$-fold less than that of thymidine 5'-triphosphate.

The data from this pilot study with three patients show that AZT nucleotides in PBMC can be measured with our method. Currently the assay is laborious and requires blood volumes that make frequent sampling unacceptable. Further modifications may improve its sensitivity and facilitate detailed studies of intracellular AZT nucleotide pharmacokinetics.

\section{Acknowledgments}

We thank the physicians, nurses, and staff of the HIV Clinic, University Hospital Zurich, for patient care and Phil Furman, Burroughs Wellcome, for providing $\left[{ }^{3} \mathrm{H}\right] \mathrm{AZT}$ and AZT-triphosphate.

\section{References}

1. Fischl MA, Richman DD, Grieco MH, et al. The efficacy of azidothymidine $(A Z T)$ in the treatment of patients with AIDS and AIDS-related complex - a double blind, placebo controlled trial. $N$ Engl J Med 1987;317:185-91.

2. Furman PA. Fyfe JA. St. Clair MH, et al. Phosphorylation of $3^{\prime}$-azido3 -dcoxythymidine and selective interaction of the 5 -triphosphatc with human immunodeficiency virus reverse transcriptase. Proc Natl Acad Sci USA 1986;83:8333-7.

3. Cheng Y, Dutchman GE, Bastow KF, Sarngadharan MG. Ting RYC. Human immunodeficiency virus reverse transcriptase. General properties and its interaction with nucleoside triphosphate analogs. J Biol Chem 1987;262:2187-9.

4. St. Clair M, Richards CA. Spector T, et al. 3'-azido-3'-deoxythymidine triphosphate as an inhibitor and substrate of purified human immunodeficiency virus reverse transcriptase. Antimicrob Agents Chemother 1987:31:1972-7

5. Huang P, Farquhar D. Plunkett W. Selective action of $3^{\prime}$-azido-3'- 
deoxythymidine 5'-triphosphate on viral reverse transcriptases and human DNA polymerases. .J Biol Chem 1990;265:11914-8.

6. Langtry HD. Campoli-Richards DM. Zidovudine: a review of its pharmacodynamic and pharmacokinetic properties, and therapeutic efficacy. Drugs 1989:37:408-50.

7. Ho HT, Hitchcock MJM. Cellular pharmacology of $2^{\prime}, 3^{\prime}$-dideoxy-2', $3^{\prime}$ didehydrothymidine, a nucleoside analog active against human immunodeficiency virus. Antimicrob Agents Chemother 1989:33: 844-9.

8. Balzarini J, Pauwels $\mathbf{R}$, Baba $\mathbf{M}$, et al. The in vitro and in vivo antiretrovirus activity, and intracellular metabolism of $3^{\prime}$-azido- $2^{\prime}, 3^{\prime}-$ dideoxythymidine and $2^{\prime}, 3^{\prime}$-dideoxycytidine are highly dependent on the cell species. Biochem Pharmacol 1988;37:897-903

9. Vogt MW, Hartshorn KI, Furman PA, et al. Ribavirin antagonizes the effect of azidothymidine on HIV replication. Science 1987;235: 1376-9.

10. Khym JX. An analytical system for rapid separation of tissue nucleotides at low pressures on conventional anion exchangers. Clin Chem 1975;21:1245-52.
11. Vogt MW, Schwarz C, Kuster H, Nadai V, Siegenthaler W, Lüthy R. Effect of daily zidovudine (AZT) pulse-therapy on replication of human immunodeficiency virus type I and type II in vitro. Antiviral Chem Chemother 1991;1:293-8.

12. Garrett $\mathrm{CH}$, Santi DV. A rapid and sensitive high pressure liquid chromatography assay for deoxyribonucleoside triphosphates in cell extracts. Anal Biochem 1979;99:268-73.

13. Frick LW, Nelson DJ. St. Clair MH, Furman PA, Krenitsky TA. Effects of $3^{\prime}$-azido-3'-deoxythymidine on the deoxynucleotide triphosphate pools of cultured human cells. Biochem Biophys Res Commun $1988 ; 154: 124-9$.

14. Stretcher BN, Pesce AJ, Wermeling JR, Hurtubise PE. In vitro measurement of phosphorylated zidovudine in peripheral blood leucocytes. Ther Drug Monit 1990;12:481-9.

15. Stretcher BN, Pesce AJ, Murray JA, Hurtubise PE, Frame PT. Lack of correlation of phosphorylated zidovudine (ZDV) in patient mononucleocytes with ZDV dose and serum concentration. Presented at the 10th AIDS Clinical Trials Group Meeting, Washington, DC, 1990. 